\title{
Os extratos de uma ontologia marxista do direito em Roberto Lyra Filho
}

\author{
Extracts of a marxist ontology of law in Roberto Lyra Filho
}

Moisés Alves Soares ${ }^{1}$

Resumo: A obra de Roberto Lyra Filho consiste em um rastrear constante da essência do direito na realidade histórico-social e aponta para realização da justiça concreta. O jurista carioca no desenvolvimento dessa síntese teórica caminha em direção a uma ontologia marxista do direito - ponto fundamental e estranhamente pouco sublinhado por seus intérpretes - apoiada nas contribuições de três gigantes do pensamento marxista: György Lukács, com sua Ontologia do Ser Social, Ernst Bloch, com seu Princípio Esperança; e, por fim, a Ontologia da Práxis presente nos Cadernos do Cárcere. Os "usos" que Lyra Filho faz dos extratos destas teorias marxistas combinadas com o pluralismo jurídico à Boaventura sua ontologia dialética do direito são ricos em possibilidades interpretativas, que serão abordadas neste estudo.

Palavras-chave: Lyra Filho; Ontologia; Utopia Concreta; Hegemonia; Marxismo

Abstract: The work of Roberto Lyra Filho consists of a constant track of the essence of the right in the historical and social reality and points

1 Professor integral do Curso de Direito da Unisociesc (Joinville). Doutorando em Direito do Estado pelo Programa de Pós-Graduação em Direito da Universidade Federal do Paraná (PPGD/UFPR). Mestre em Teoria e Filosofia do Direito pelo Curso de Pós-Graduação em Direito da Universidade Federal de Santa Catarina (CPGD/UFSC). Pesquisador do Núcleo de Estudos Filosóficos (NEFIL/UFPR). Secretário nacional do Instituto de Pesquisa, Direitos e Movimentos Sociais (IPDMS). 
to concrete realization of justice. The carioca's jurist in the development of this theoretical synthesis walks toward a marxist ontology of law - fundamental point and strangely little emphasized by their interpreters - supported the contributions of three giants of marxist thought: György Lukács, with his Ontology of Social Being, Ernst Bloch with its The Principle of Hope; and finally, the Ontology of Praxis present in Prison Notebooks. The "uses" that Lyra Filho makes of extracts of these Marxist theories combined with Boaventura's legal pluralism in its dialectical ontology of law are rich in interpretive possibilities, which will be focused in this study.

Keywords: Lyra Filho; Ontology; Concrete Utopia; Hegemony; Marxism

\section{O RESGATE DA ABORDAGEM ONTOLÓGICA}

A presença de Roberto Lyra Filho é, indiscutivelmente, marcante no cenário da teoria jurídica crítica brasileira. Neste ano (2016), que fazem exatos 30 anos da morte e, igualmente, celebram-se 90 anos de seu nascimento, é necessário avaliar e rememorar seu importante legado. Seus diálogos e relevantes contribuições navegam por boa parte do que se costuma denominar enquanto os campos das disciplinas formativas do direito: um estudo do direito penal que conflui para sua original "criminologia dialética"; uma sociologia do direito que constituiu o conhecido "direito achado na rua"; por fim, não exaurindo outros elementos da totalidade de seu pensamento, uma filosofia/teoria crítica do direito heterodoxa, porém em pleno diálogo com o marxismo, intitulada de "NAIR".

Toda construção de Lyra Filho perpassa, em sua multiplicidade, invariavelmente, pela procura incessante em captar a essência do direito na realidade histórico-concreta. Mas é preciso deixar claro que, para o jurista carioca, "nada é, num sentido perfeito e acabado; que tudo é, sendo". O que não implica uma procura apriorística para "determinar a 'essência' do Direito - o que, apesar de tudo, ele é, enquanto vai sendo: o que surge de constante, na diversidade, e que 
se denomina, tecnicamente, ontologia". Nesse sentido, seu impulso em direção à ontologia - ponto fundamental e estranhamente pouco sublinhado por seus intérpretes - deve-se a presença da prioridade do real (ser), em oposição à hegemonia de um dever-ser hipostasiado, e a opção por uma abordagem absolutamente dialética (mesmo que, por vezes, haja um insuspeito flerte com o hegelianismo) (LYRA FILHO, 2006, p.12-13).

A proposta de uma ontologia no século $X X$, ainda mais uma ontologia jurídica, carrega consigo uma desconfiança relativamente justificada por parte dos teóricos dos mais diversos matizes. Pois "não teria toda a evolução do pensamento, desde a Idade Média até as últimas correntes filosóficas do século que agora se encerra, demonstrado definitivamente que a ontologia nada mais passa de uma vã tentativa de fixar em categorias não-históricas a efemeridade essencial da existência humana?" (LESSA, 2010, p.160). A essa questão Lyra Filho responde que "durante muito tempo, quis-se afirmar que toda ontologia é, por natureza, um produto 'metafísico' e idealista. Não é verdade; e basta, para demonstrá-lo, o exemplo de dois eminentes marxistas ${ }^{2}$, que, com todo seu vezo materialista, nada obstante se dedicaram aos estudos ontológicos. De fato a ontologia não é 'metafísica' - fixista ou idealista - por definição; no máximo por desvio" (LYRA FILHO, 1981a, p.22).

O empreendimento de sua ontologia materialista do direito concretiza-se apoiada em três gigantes, pois como o próprio Lyra Filho gostava de relembrar: "o pigmeu trepado às costas do gigante, pode enxergar mais longe do que este". A inspiração direta parte da obra de Lukács: "Ontologia do Ser Social. [...] Ali há poderosas sugestões: a ontologia jurídica pode contrapor-se a todo idealismo, tomando os dados empíricos, a fim de reelaborá-los, em busca das 'categorias, como formas

2 Lyra Filho refere-se aos húngaros György Lukács e Imre Szabò. O primeiro dispensa apresentações, por outro lado, o segundo trata-se de jusfilósofo que teorizou sobre uma ontologia jurídica apoiada em Marx. Muito embora cite Szábo a título de exemplo, pouca influência exerceu em seu pensamento, chegando a afirmar que "a concepção que tenho dessa ontologia [jurídica] difere da que Szabò extraiu duma leitura de Marx" (LYRA FILHO,1981a, p.23). 
de ser e determinações da existência'; isto é, num salto, em que o ser e a essência resultam 'geneticamente deduzidos de suas formas de transição'” (LYRA FILHO, 1981a, p.21).

A outra referência em que se baseou - muito provavelmente, pela necessidade de inserir uma ontologia da política (utopia concreta) em sua teoria, ponto deficiente do projeto inacabado de Lukács - foi a perspectiva filosófica de Ernst Bloch. Ele utiliza-se da ontologia da esperança ou do ainda-não-ser de Bloch para caminhar, superando as posições que abordam o ser do direito como pura negação, na direção da "reconstrução das categorias jurídicas, sob a ótica a ótica da filosofia da práxis" (MASCARO, 2008, p.155).

Ainda, trabalhando a partir da chave explicativa do devir histórico constituído pela práxis social, é que Lyra Filho avalia a concretude da forma jurídica. $\mathrm{O}$ direito é visto como uma relação social constituinte aos conflitos políticos, que transbordam a questão da luta de classes e se enfeixam nas múltiplas dimensões da opressão (racial, gênero, étnica, etc.). Para analisar esse contexto dialético, o jurista carioca lança mão dos geniais apontamentos de Antonio Gramsci nos Cadernos do Cárcere - com a forte influência do tom imprimido por Carlos Nelson Coutinho na recepção do marxista sardo -, em especial, de sua teoria da hegemonia. Nesse sentido, há a inspiração em outra "autêntica ontologia materialista e dialética da práxis política”, pois, em Gramsci, está em marcha "uma crítica ontológica da política, que, em seus resultados teóricos, cumpre as indicações metodológicas da 'crítica da economia política' marxiana" (COUTINHO, 1996, p.159).

E é a partir de como Roberto Lyra Filho se apropria e articula as contribuições destes gigantes da filosofia marxista - teorização de extrema originalidade, visto que, se a recepção dos Cadernos do Cárcere era fato recente no cenário brasileiro, por sua vez as obras Ontologia do ser social e Principio Esperança eram relativamente desconhecidas e com trabalhos escassos a seu respeito nas ciências sociais e quase que inexistentes na esfera jurídica - que se verá como se estrutura sua proposta de uma ontologia dialética do direito iconoclasta e totalmente contrastante com o marxismo vulgar. 


\section{A PROTOFORMA DA ONTOLOGIA LUKACSIANA EM LYRA FILHO}

O primeiro gigante, György Lukács ${ }^{3}$, ao teorizar no terreno da investigação ontológica, não tem outra intenção, frente à alienação e a ilusão da impossibilidade de os homens constituírem conscientemente a sua história, do que "reafirmar as teses de Marx acerca da radical historicidade e sociabilidade do mundo dos homens e demonstrar a possibilidade ontológica (que não deve ser confundida com possibilidade imediata) da revolução socialista" (LESSA, 1997, p.89). O filosofo húngaro, deste modo, contrapõe-se "à concepção conservadora segundo a qual aos homens corresponde uma essência a-histórica de proprietários, e que, por isso, não há como ser superada a sociedade capitalista" e defende "que não há limites ao desenvolvimento humano, a não ser aqueles construídos pelos próprios homens" (LESSA, 2007, p.13). A ontologia lukacsiana exprimiu-se, portanto, como uma potente arma crítica contra a reificação e uma revitalização da noção de sujeito revolucionário.

No entanto, nem sempre Lukács viu a ontologia com bons olhos. Após ter combatido duramente "às correntes irracionalistas modernas em seu livro A destruição da razão (escrito nos anos 30-40 e publicado em 1953), o último Lukács passou a perceber a importância crescente que o neopositivismo - com sua negação da ontologia, da história e da totalidade - havia assumido na ideologia burguesa contemporânea". Além disso, dentro do campo da esquerda, "o stalinismo seria responsável pela introdução de elementos neopositivistas e anti-ontológicos também na reflexão de inspiração marxista" (COUTINHO, 1996, p.145-46). Nesse sentido, sua virada em direção à ontologia, sem deixar de lado a crítica ao irracionalismo, ocorre como uma dupla

3 "Os quatros livros elaborados por Lukács na sua maturidade - O jovem Hegel, A destruição da razão, a Estética e a Ontologia do ser social - se inserem, de acordo com nossa visão, num conjunto especificamente concebido: Lukács é um dos últimos pensadores sistemáticos deste século que chegou a propor em suas obras uma verdadeira 'filosofia do sujeito', formulando as condições da verdadeira humanistas do homo humanus". TERTULIAN, Nicolas. Lukács Hoje. In: LESSA, Sergio; PINASSI, Maria Orlanda (orgs.). Lukács e a atualidade do marxismo. São Paulo: Boitempo, 2002, p.45. 
reação diante do neopositivismo e do marxismo vulgar, hegemônicos naquele momento histórico dos dois lados do muro - exatamente os mesmos adversários que provocam Lyra Filho a construir sua aproximação ontológica do direito.

O filósofo húngaro refutava o neopositivismo - "que tendia a reduzir a realidade à sua compreensão cognitiva, àquilo que é nela mensurável e redutível a termos lógicos" -, a fim de "restabelecer a autonomia ontológica do real, a sua totalidade intensiva e a sua irredutibilidade à pura manipulação". Debatia-se, igualmente, contra "a tendência do marxismo dogmático em privilegiar a categoria da necessidade, tomando hipertrófico seu papel na história, levava Lukács a refletir a fundo sobre as relações entre as categorias modais (possibilidade, necessidade, casualidade) e a reexaminar criticamente os próprios fundamentos do pensamento de Marx" (TERTULIAN, 1996, p.61).

Sincronicamente, Lyra Filho, em suas reverberações na esfera jurídica, situava-se em oposição ao "positivismo lógico", que, ao partir das "leis ou, subsidiariamente, de outras tantas normas sociais da ordem instituída", constitui-se "numa espécie de hierarquia, que culmina em ordenamento único, pleno, hermético e consagrado, sob a égide estatal" (LYRA FILHO, 1981b, p.17). Tal "circulo vicioso do positivismo, reduzindo arbitrariamente todo direito à norma formalizada, nega, depois a natureza jurídica do que não se adapta ao seu modelo. [...] É o leito de Procusto ontognosiológico" (LYRA FILHO, 1980a, p.31-2). Era combatente, também, na mesma trincheira de Lukács, ao marxismo vulgar, que compreende o "fenômeno jurídico enquanto simples norma da classe dominante", pois "as simples derivações infra-estruturais encurtam a visão, tornado-a simplista e unilinear. É, numa palavra, mecanicismo" (LYRA FILHO, 1980b, p.16).

É com base na ontologia materialista de Lukács, que Lyra encontra "a profunda concepção marxiana do fenômeno e da essência na processualidade do ser social como um todo" (LUKÁCS, 1979, p.55). Para tal concepção radicalmente histórica não é possível conceber a essência como um ente estático-estacionário, como um momento que determina o processo do exterior, ao invés disso, ela é parte integrante e imprescindível de toda processualidade conjuntamente com esfera 
fenomênica ${ }^{4}$. Desta feita, a essência e o fenômeno são categorias que possuem o mesmo estatuto ontológico, sendo "produtos das mesmas posições teleológicas. [...] A dialética ontológica entre essência e fenômeno seria impossível se eles não surgissem de uma tal gênese fundamentalmente unitária e se esta unitariedade não fosse dinamicamente conservada" (LUKÁCS, 1981(II**), p.369).

Há, portanto, uma clara ruptura de Lukács com o trato ontológico tradicional, pois, para o filósofo húngaro, existe "uma esfera de determinações da essência sobre os fenômenos, como também há uma outra, dos fenômenos sobre o desenvolvimento das determinações essenciais" (LESSA, 1999, p.26). Assim, "no ser social, o mundo dos fenômenos não pode de modo algum ser considerado um simples produto passivo do desenvolvimento da essência, mas, pelo contrário, tal inter-relação entre essência e fenômeno constitui um dos mais importantes fundamentos reais da desigualdade e da contraditoriedade no desenvolvimento social" (LUKÁCS, 1981 (II**), p.472). Deste modo, ambas as esferas - essência e fenômeno -, na concepção lukácsiana, são, igualmente, representativas do ser e a distinção entre elas decorre da peculiar relação que cada uma mantém com a categoria da continuidade. A diferença entre essência e fenômeno situa-se no modo de se relacionar na complexidade de um processo histórico-social, isto é, o que é essencial - longe de ser imutável - expressa os traços de continuidade da historicidade, conferindo unitariedade última à processualidade, e, por sua vez, os elementos fenomênicos são definidos pela capacidade de diferenciação em momentos singulares.

Não existe, desta maneira, "qualquer anterioridade do essencial em relação ao processo: a essência vem a ser como determinação do

4 A questão chave para o esclarecimento da virada ontológica feita por Lukács é o tratamento analítico dado a categoria de substância. Uma concepção que pressupõe o abandono radical da validade eterna de valores transcendentes ao processo, pois para Lukács substancialidade não é, como de costume, "uma relação estático-estacionária de auto-conservação, que se contraponha que se contraponha em termos rígidos e excludentes ao processo do devir; ao contrario, ela se conserva em essência, mas de modos processual, transformando-se no processo, renovando-se, participando do processo" (LUKÁCS, 1979 p.161). 
processo ${ }^{5}$. A gênese do processo é a gênese de sua essência (e, mutatis mutandis, de sua esfera fenomênica); seu desenvolvimento é o desenvolvimento de suas determinações essenciais e fenomênicas; seu término corresponde ao fim do que Ihe foi essencial e fenomênico" (LESSA, 1999, p.30). Isto significa que nada, nem mesmo a mais convergente determinação essencial, existe para além do processo histórico. A historicidade constitui-se, assim, em uma categoria efetivamente universal na ontologia de Lukács, abrangendo - em ruptura com todas as ontologias anteriores - inclusive e fundamentalmente a essência. A essência, portanto, é tão histórica quanto o fenômeno.

O jurista carioca vê, nesta radical historicidade da ontologia do ser social, o caminho para combater as principais ideologias jurídicas (neo) positivismo e jusnaturalismo - e compreender o que o direito "vem a ser, nas transformações incessantes do seu conteúdo e forma de manifestação concreta dentro do mundo histórico e social" (LYRA FILHO, 2006, p.13). Ao procurar esta essência em movimento do Direito - "encarnação da duração na mudança" ou "continuidade tendencial última” (LUKÁCS, 1981, p.373-75) -, Lyra Filho ampara-se, claramente, na ontologia de Lukács, e, assim o diz, que "fica ressalvado que uma ontologia dialética, tal como indicava o filosofo húngaro Lukács, tem base nos fenômenos e é a partir deles que procura deduzir o 'ser' de alguma coisa, buscado, assim, no interior da própria cadeia de transformações" (LYRA FILHO, 2006, p.13).

No entanto, apesar de ter como ponto de partida ontológico o seu aporte categorial, ele não chega às mesmas conclusões que o filósofo húngaro sobre o complexo jurídico, para quem "o direito, surgido porque existe a sociedade de classes é, por sua essência, necessariamente um direito de classe: um sistema para ordenar a sociedade segundo os interesses e o poder da classe dominante" (LUKÁCS, 1981(I I*), p.369). Deste modo, "o ordenamento jurídico em sentido próprio nasce somente quando os interesses divergentes, que em si

5 A "essência, na acepção lukacsiana, é o complemento de determinações que permanece ao longo do desdobramento categorial do ser; a essência são os traços mais profundos que articulam em unidade os heterogêneos momentos que se sucedem ao longo do tempo. A essência é o lócus da continuidade" (LESSA, 2002, p.51). 
poderiam conduzir em cada caso singular para uma solução violenta, são reduzidos ao mesmo denominador jurídico, são homogeneizados no direito. Este complexo, portanto, nasce quando se torna socialmente importante, assim como a sua superfluidade social é o veículo de sua extinção" (LUKÁCS, 1981(II*), p.220).

Não pôde, Lyra Filho, concordar com Lukács sobre uma teoria de pura negação da esfera jurídica no comunismo, pois compreende que carece "do ponto de vista marxiano, uma disposição de suas idéias jurídicas, no padrão dialético da afirmação, da negação e da negação da negação do direito" (LYRA FILHO,1983a, p.60). É sintomático, portanto, que, muito embora se utilize de seu substrato teórico fundamental, Lyra Filho aponte para o vir-a-ser e se inspire, igualmente, em busca de uma utopia concreta para o direito (Aufhebung), na ontologia do ainda-não-ser de Ernst Bloch e na ontologia da práxis de Gramsci.

\section{A CENTRALIDADE DA UTOPIA CONCRETA: A ONTOLOGIA DO AINDA-NÃO-SER}

Em O Princípio Esperança, Bloch elabora um "projeto global de uma filosofia materialista do futuro cujo âmago é uma ontologia do ainda-não-ser, que muito mais que todas as outras ontologias da modernidade, baseia-se na teoria das potencialidades imanentes ao SER que não foram exteriorizadas" (MÜNSTER, 1993, p.14). Para o marxista alemão, o mundo não é um sistema fechado ou um processo acabado, pelo contrário, ele possui um horizonte aberto e é cheio de possibilidades ainda-não concretizadas. A realidade não aparece somente como a que se tornou existente, sem vida, mas "como [um] entrelaçamento de caminhos dos processos dialéticos, que ocorrem num mundo inacabado, num mundo que jamais seria modificável sem o gigantesco futuro, possibilidade real, nele contido" (BLOCH, 2005, p.221). O real, deste modo, não se esgota no imediato e aponta sempre para um devir rico em bifurcações. Mas como Bloch estrutura esse possível - toda "a ontologia do ainda-não-ser se fundamenta sobre a análise da categoria possibilidade": "a categoria das categorias" (ALBORNOZ, 1985, 
p.71-79) - é determinante para o caráter materialista ${ }^{6}$ e absolutamente dialético de sua ontologia.

A categoria possibilidade, para Bloch, na história do pensamento filosófico, "com certeza é a que menos foi rastreada ontologicamente; por isso, ela ocorre tradicionalmente só na lógica formal. Mesmo quando a doutrina das categorias se ocupa do possível, este é considerado preponderantemente apenas como determinação do conhecimento e não do objeto" (BLOCH, 2005, p.238). Em oposição a essa concepção estático-lógica do possível, Bloch estrutura a categoria possibilidade a partir da concepção de matéria dinâmica em Aristóteles. Para quem, "a matéria não é somente conforme a possibilidade, ou seja, aquilo que, em cada caso, condiciona de acordo com a dada medida do possível, mas ela é o sendo-em-possibilidade, ou seja, o útero da fertilidade - em Aristóteles todavia ainda passivo -, do qual descendem de modo inexaurível todas as formas de mundo". Deste modo, a matéria assume "uma latência no rumo dos conteúdos reais-objetivos de sua esperança: como o fim de sua auto-alienação e da objetividade afetada por elementos estranhos, como matéria das coisas para nós". Para Bloch, com esta definição foi "inaugurado o aspecto amigável, se não esperançoso, da possibilidade real-objetiva, por mais demorada que tivesse sido sua apreensão" (BLOCH, 2005, p.205-207).

Tal processualidade da matéria confere diversas perspectivas a respeito do que ainda-não-é, por isso, para captar os vários estratos desse pode-ser, o marxista alemão estrutura alguns níveis de possibilidade: o possível formal; possível objetivo-factual ou possível objetivo ao nível dos fatos ou, ainda, possível subjetivo; possível conforme a estrutura do objeto real ou o possível objetivo ou, mesmo, possível objetivo-coisal; e, por último, o possível dialético ou possível objetivamente real ou, tomado em outra terminologia, possível objetivo-real determinante para compreender o pensamento de Lyra Filho.

6 "A ontologia fundamentadora do pensamento de Bloch - embora enquanto ontologia permanece materialista: passa o 'não' a dar-se logo como pulsão, carência, aspiração, fome, que são ainda-não-ter, ou não-ter que indica ainda-não-ser concreto, com raiz na matéria em que o mundo e homem estão dialeticamente envolvidos, mergulhados, em processo e ação"( ALBORNOZ, 1985, p.49). 
O possível formal, nível mais raso e frágil da categoria possibilidade, encontra-se como um pode-ser apenas no mundo dos signos, uma vez que, tendo em vista a realidade, deverá ocorrer um não-possível. Isto é, o marxista alemão, ao conceber o possível formal, diferencia entre o "possível pensável - embora seja uma contradição e se dê como absurdo, portanto, sendo irrealizável, e na realidade, impossível, mas impossível só no plano do ser - e o apenas dizível que não tem significado e não encontra eco na inteligência que o recebe: o não-senso impossível no âmbito do entender mesmo" (ALBORNOZ, 1985, p.53). Deste modo, o possível formal, "diferentemente da tolice meramente pronunciável, é algo que pode perfeitamente ser pensado; é um poder ser formal, pois passível de ser pensado é tudo que de alguma forma pode ser concebido como estando em relação" (BLOCH, 2005, p.222). No plano teórico-político, "é o possível do otimismo que ignora, de propósito ou não, os obstáculos, e crê, a priori, na possibilidade de um progresso linear.[..] Normalmente é este possível que é criticado pelos que identificam a esperança com o otimismo: reduzem a consciência antecipadora a um vago utopismo" (FURTER,1974, p.112).

Por sua vez, o possível objetivo-factual "é expressão da previsão e da opinião fundada ou suposição sobre a possibilidade de ser de uma coisa; mas a fundamentação desta suposição ainda não se dá de modo pleno. Suas determinações ainda não são inteiramente conhecidas" (ALBORNOZ, 1985, p.54). Um possível que não se constitui em somente uma projeção do pensamento, mas como uma abertura na realidade condicionada por um conhecimento insuficiente, em termos gnosiológicos, da totalidade do objeto - uma possibilidade que não analisa o objeto em si, mas uma virtualidade factual limitada pelo desenvolvimento teórico (uma suposição fundamentada da realidade e suas projeções). Nesta direção, "designa, assim, sempre um estado gradual da fundamentabilidade objetivo-científica em conformidade com o caráter incompleto do conhecimento científico das condições factualmente disponíveis" (BLOCH, 2005, p.224). Aqui, aproximando tal esfera do possível para o campo da (economia) política, estaria situado o momento da conjectura, com base em juízo problemático, ainda que autêntico, das potencialidades e probabilidades do real. 
No terceiro nível, o possível conforme a estrutura do objeto real, "ao contrário do possível subjetivo, que não se funda na própria virtualidade do objeto neste caso se abre claramente a mirada ontológica da possibilidade" (MASCARO, 2008, p.127). Transpõe-se da esfera objetividade, referente unicamente à teoria do conhecimento, para teoria do objeto do conhecimento estribada no objeto real - uma virada ontológica, portanto -, mesmo que ainda seja uma teoria categorial do objeto. Por esta via, a demarcação do possível objetal não é a convivência com condicionantes não suficientemente conhecidas, mas disposições do objeto não plenamente manifestas. Nesse estrato, ingressa-se "na camada de representação do caráter objetal", "o lugar das categorias como modos ou formas de existência mais gerais, e, assim, típico-características" (BLOCH, 2005, p.227-228).

Nesse sentido, entrelaçam-se em uma dualidade estruturalmente determinada pela representação do objeto dois tipos de condições da possibilidade: as internas e as externas. Isto é, por um lado, uma condição parcial interna enquanto possibilidade ativa, envolvendo a capacidade/potência de "poder-tornar-se-diferente", bem como, por outro lado, uma condição parcial externa no sentido passivo, significando a potencialidade histórica presentes nas relações sociais de "poder-fazer-diferente". É com esta possibilidade aberta conforme o objeto, portadora de certo idealismo objetivo, que o homem põe em marcha através da forma política da subjetividade transformadora às potencialidades proporcionadas pelo amadurecimento dos elementos externos. (BLOCH, 2005, p.229).

Mas é unicamente no possível objetivo-real ou dialético - ponto fundamental para compreensão da concepção dialética lyriana - que Bloch supera essa suposta dicotomia e recoloca a relação entre a atividade humana e o dinamismo da matéria. Pois, para o marxista alemão, "justamente os extremos até o momento mantidos no maior distanciamento possível - ou seja: futuro e natureza, antecipação e matéria - coincidem na radicalidade oportuna do materialismo dialético-histórico". Assim, embora as determinações/latências do futuro não estejam todas contidas no substrato material, "sem a matéria não há solo para a antecipação (real); sem antecipação (real) não há horizonte 
concebível para a matéria" (BLOCH, 2005, p.234). Deste modo, Bloch coloca centralidade, na contramão de Freud, nos sonhos diurnos que consistem no "lugar de nascimento do desejo e da imaginação, como 'guia' das 'imagens do desejo' de algo que ‘ainda-não-é'”(MÜNSTER, 1993, p.26). São justamente essas projeções materiais do desejo que possuem a característica de antecipação do futuro, isto é, o local privilegiado da efervescência da concretude utópica tão insistentemente referido pela ontologia dialética do jurista carioca.

O possível dialético, portanto, não reside "numa ontologia acabada do ser do que existiu até o momento, mas na ontologia, a ser renovadamente fundada, do ser do ainda-não-existente, que descobre futuro até mesmo no passado e na natureza como um todo" $(\mathrm{BLOCH}, 2005$, p. 234). Tal possibilidade real é o momento, no âmbito categorial, de projeções que estão adiante do movimento material em sua processualidade. Em síntese, expressa-se num "processo permanente, uma imagem ativa da esperança de um mundo melhor, mediada pela tendência, um ideal instigante, um símbolo de teor profundo: é isso que permanece sendo as perspectivas reais, elas próprias antecipadoras, da possibilidade real"( BLOCH, 2005, p.238). É neste nível do possível que se pode realizar a utopia concreta, "capacidade utópica colocada sobre os próprios pés", "o ponto de contato entre sonho e vida, sem o qual o sonho produz apenas utopia abstrata e a vida, por seu turno, apenas trivialidade" (BLOCH, 2005, p.145). Ao contrário, portanto, de qualquer utopismo escapista/idealista, para Bloch, não há realismo autêntico sem o dimensionamento das potencialidades dessas bifurcações da realidade ${ }^{7}$.

A utopia, em Bloch, emerge, portanto, como um despertar dessas "possibilidades virtuais do real; o desejo de outra situação e a prospecção para o futuro com base naquelas possibilidades, [...] [um impulso] para ação que modifique esse dado que hoje se nos apresenta como real” (ALBORNOZ, 1985, p.30). Nesse sentido, a utopia está indissociavelmente voltada para o futuro: vir-a-ser. Mas "este voltar-se para

7 "O real aparece como aquilo que ele é in concreto: como entrelaçamento de caminhos dos processos dialéticos, que ocorrem num mundo inacabado, num mundo que jamais seria modificável sem o gigantesco futuro, possibilidade real, nele contido" (BLOCH, 2005, p.221). 
o futuro tampouco é um sonhar ligeiro, ou uma confiança ingênua no amanhã, mas o resultado de uma severa crítica do presente. O Principio de esperança que anima a utopia faz da crítica do atual e, em particular, dos fracassos das nossas atuações, o momento decisivo da construção de uma utopia militante e concreta" (BLOCH, 2005, p.152). Deste modo, "importa para a utopia concreta compreender com exatidão o sonho de seu objeto, inerente ao próprio movimento histórico. Como uma utopia mediada com o processo, importa-lhe destacar as formas e os conteúdos que já se desenvolvem no seio da sociedade atual" (BLOCH, 2006, p.177).

A utopia concreta proposta por Bloch se estrutura "nos dois elementos fundamentais da realidade compreendida em termos marxistas: em sua tendência, como tensão do que está na vez mas é tolhido; e em sua latência, como elemento correlato das possibilidades reais objetivas ainda não realizadas no mundo" (BLOCH, 2006, p.177). Dessa forma, "a função utópica é a única transcendente que restou, e a única que é digna de permanecer: uma função transcendente sem transcendência" (BLOCH, 2006, p.146). Sobre essa positividade da utopia concreta, Bloch ressalta "sua força criadora e 'subversiva', porém, num sentido construtivo, anunciador e antecipador de uma vontade futura mais firme e clara da emancipação, da reconstrução da sociedade segundo as idéias de igualdade, de dignidade humana, de fraternidade e liberdade (MÜNSTER, 1993, p.24-5).

O marxista alemão, no interior da utopia concreta, opera uma distinção entre utopias sociais e utopias jurídicas. "As utopias sociais estão, principalmente, dirigidas à felicidade, ou pelos menos, a eliminação das necessidades e das circunstancias que mantêm ou produzem aquela. As teorias jusnaturalistas, por sua vez, estão, predominantemente, dirigidas à dignidade, aos direitos do homem, às garantias jurídicas de segurança ou liberdade humana, enquanto categorias do orgulho humano". Dessa forma, "a utopia social está dirigida, sobretudo, à eliminação da miséria humana, enquanto que o Direito Natural está dirigido, antes de tudo, a supressão da humilhação humana" (BLOCH, 1980, p.209). No entanto, não há contradição entre as duas expressões da utopia concreta, "Bloch entende que o campo da felicidade 
do homem, do qual se situa sua emancipação econômica, o fim da exploração do trabalho, o fim das classes e da mais-valia, não esgota necessariamente o campo da dignidade do homem, cujo estatuto, embora resultante de um mesmo movimento histórico-social de emancipação, é distinto e específico" (MASCARO, 2008, p.122).

Em especial, no que se refere à utopia jurídica blochiana, a questão central encontra-se na centralidade dada ao direito natural. Para Bloch, o direito natural é portador inextinguível de uma perspectiva do que o direito ainda-não-é, um campo de possibilidade além e em oposição ao direito posto. Em sua origem, "ele é ou deveria ser imutável e, como direito natural, superior a todos os estatutos arbitrários. Justifica, sim, encoraja quando necessário, a resistência contra o estatuto, a partir de uma posição superior à da lei escrita" (BLOCH, 2006, p.89). Mas, no entendimento do revolucionário alemão, "o autêntico Direito natural, baseado na vontade racional liberada, postulava uma justiça que havia que conquistar em luta; não uma justiça provinda do alto que, distributiva ou retributivamente, prescreve a cada um sua parte, mas uma justiça ativa, uma justiça desde baixo" (BLOCH, 1980, p.XI-XII).

A ontologia da esperança, portanto, conjuga "utopia social e direito natural [...]; marchando juntos, porém, desgraçadamente, não golpeando juntos". Historicamente, o direito natural de combate possui uma coexistência genética contraditória entre um imperativo econômico e um potente caráter humanista. Por isso, "não há uma instauração verdadeira dos direitos do homem sem por fim a exploração, bem como não há verdadeiro termino da exploração sem a instauração dos direitos do homem". Nesse sentido, a utopia concreta carrega uma normatividade alternativa inspirada no direito natural, intentando a transformação das "facultas agendi dos homens desalienados em norma agendi de uma comunidade finalmente desalienada" (BLOCH, 1980, p. XI-XII).

É, justamente, inspirado nesta antecipação real em direção ao que ainda-não-é no campo da utopia concreta, que Lyra Filho encontra a outra fonte para construção de sua ontologia dialética do direito. $O$ próprio jurista carioca frisa que "não somos utópicos, senão no sentido nobre da palavra, porque ninguém participa da transformação do mundo sem figurar grandes metas, situadas além dos limites tópicos. Se há 
utopia, ela vem nos termos de Bloch, isto é, como o princípio-esperança, regendo uma teoria apoiada na ciência e na práxis e voltada para a defesa da liberdade individual e coletiva - que se co-implicam" (LYRA FILHO, 1984, p.37). Uma utopia no sentido "poderoso e realista, de Ernst Bloch, que vê a utopia como a imagem das metas perseguidas, na construção do futuro, guiando cada palavra, cada gesto, cada atitude, na linha coerente da Justiça Social” (LYRA FILHO, 1981a, p.41).

O caminho da utopia concreta perseguida por Lyra Filho permite compreender o direito como um vir-a-ser: "a alma de uma práxis destinada a alargar os horizontes, dentro das próprias limitações da conjuntura emergente" (LYRA FILHO, 1980, p.28). O jurista carioca procura extrair da concepção utópica blochiana, mesmo com ressalvas - como será visto -, elementos para constituir a negação da negação do direito. Nesse sentido, Lyra Filho considera que "o aspecto jurídico do processo é o que delineia a forma positivada, alcance próprio dos princípios da práxis social justa e do controle social legítimo, com a indicação das normas em que ele venha a se organizar, no modelo atualizado e vanguardeiro de organização social da liberdade. E isto se resume, repetimos com o filosofo marxista Ernst Bloch, em determinar 'a instauração da faculdade de agir' (das classes e grupos), sem alienação, 'nas normas de agir duma comunidade enfim não alienada'”. Em oposição à idéia da extinção do direito, pensa que "no socialismo, o aspecto jurídico, ao invés de sumir, ganha mais relevo, como dizia ainda Bloch, enquanto 'os Direitos Humanos não serão menos militantes como direito à crítica, inexoravelmente objetiva e prática, pelo avanço da construção socialista, dentro dum quadro de solidariedade'" (LYRA FILHO, 2006, p.101).

No entanto, apesar de apontar para um futuro capaz de negar os processos de alienação, a utopia jurídica de Bloch pressupõe uma postura antinormativista de total destruição do direito positivo burguês ao gosto de Lênin e Pachukanis - ponto nada ressaltado por Lyra FiIho. Nesta questão, Bloch entende que "como a propriedade privada é a categoria dominante da jurisprudência, não há dúvida de que com a eliminação da propriedade privada (dos meios de produção), a jurisprudência perderá completamente sua função, isto é, perecerá por 
si [...] A exploração impôs a lei, e somente com a desaparição de sua economia desaparecerá também a lei" (BLOCH, 1980, p.187-188). A forma jurídica reivindicada por Bloch é o direito natural depurado dos ranços burgueses e vinculado à utopia da concretização da dignidade humana concebida a partir de outro padrão de sociabilidade. Assim, "dirá Bloch que pertence ao marxismo a luta pelos direitos do homem, entendidos não a partir da metafísica que lhe deu formação, e sim por meio da luta pela dignidade humana" (MASCARO, 2008, p.161-62) ${ }^{8}$.

Um direito natural que se constrói como utopia jurídica a partir das heranças aproveitáveis da tradição jusnaturalista, isto é, todas as revoluções ou mesmo utopias não realizadas carregam consigo um "conteúdo utópico-concreto de uma promessa que visa orientar e impulsionar a revolução real. Este é o conteúdo dos direitos do homem" No interior dessas heranças aproveitáveis, como promessas não levadas a cabo por seu sujeito histórico, que compõem os direitos humanos estão os postulados proclamados pela revolução francesa: "liberdade, igualdade, fraternidade, a intentada ortopedia do andar ereto, do orguIho viril, apontam para muito mais além do horizonte burguês" (BLO$\mathrm{CH}, 1980$, p.177). Trata-se, claramente, da utopia jurídica golpeando conjuntamente com a utopia social, uma vez que um ideal de justiça representado pelo direito natural atua em estrita oposição ao direito posto. O marxista alemão chega a afirmar que "o teor fundamental do direito natural radical contra o Estado é a sociedade sem classes, o reino da liberdade" - "pela primeira vez uma 'polis', mas sem 'politeia'" (BLOCH, 1980, p.279 e 232).

Chega-se, aqui, no limítrofe da apreensão lyriana de Bloch. A ontologia do ainda-não-ser ou da esperança é aparato categorial estruturante da teoria dialética do direito de Lyra Filho, mas ela não se ajusta, especialmente a sua aplicação ao campo do direito, "às tentativas neo-marxistas à Bloch", "porque estas regridem ao jusnaturalismo antinômico" (LYRA FILHO, 1981a, p.36). Criam "um dualismo antinômico entre o Direito legitimo e o direito vigente - sem ver o meio dialético de

8 "Não há direitos inatos, uma vez que todos são adquiridos ou serão, todavia, adquiridos em luta"(BLOCH, 1980, p.192). 
fundir esses opostos e superar as contradições, exceto, porventura, nalgum aparelho sobrepairante aos conflitos sociais, que acaba tombando, em rodeios torturados, no velho conto do vigário estatal" (LYRA FILHO, 1984, p.16). Assim, ele se afasta de um suposto transcendentalismo de Bloch, ao buscar uma teorização dialética do processo histórico e da constituição de um direito autêntico. Tal "novo direito exige que se observe a realidade jurídica, enquanto emanada de uma práxis e pluralidade dos ordenamentos, em perspectiva libertadora, engajada e com sentido político bem definido" (LYRA FILHO, 1980a, p.19).

\section{O (AB)USO DA ONTOLOGIA DA PRÁXIS DE GRAMSCI: A AMPLIAÇÃO DO DIREITO A PARTIR DO PLURALISMO JURÍDICO}

O jurista carioca, como foi visto, ao buscar apreender a essência do direito em sua imanente historicidade faz uso explícito da ontologia de Lukács como enquadramento dialético global de sua filosofia jurídica, bem como ao projetar o futuro - a negação da negação - combina o aporte lukacsiano com a ontologia do ainda-não-ser de Bloch, tracejando no campo da possibilidade dialética a utopia concreta de um direito autêntico que virá-a-ser. Apesar do aparato categorial de fundo apoiar-se nestas duas grandes ontologias marxistas, Lyra Filho, na análise específica do direito, não chega às mesmas conclusões de Lukács e Bloch: extinção da mediação jurídica e o florescimento da ética; fenecimento do direito, enquanto normas positivadas, e aposta na utopia jurídica representada no direito natural, respectivamente. Neste ponto, Lyra faz, como diria Portantiero, um "uso de Gramsci"9, visando a partir da filosofia da práxis ampliar a concepção instrumen-

9 Compreende-se a noção de um "uso de Gramsci" enquanto um alargamento/manipulação do sentido do texto, onde suas notas "transformam-se em um espaço vazio, apto para receber qualquer conteúdo, para ser submetido a usos diversos segundo as necessidades de cada momento". As apropriações de Gramsci são das mais variadas: leninista, uma referência como continuador da obra já transformada em doutrina, e, portanto, um legitimador da linha soviética; conselhista, uma espécie de profeta do operaísmo italiano; um anunciador de uma estratégia de frente ampla popular; socialdemocrata, um teórico da luta institucional por reformas graduais ao socialismo, etc. No caso de Lyra Filho é uma 
tal/mecanicista acerca do direito, colocando-o como uma das esferas passíveis de disputa pela hegemonia política da sociedade - a longa marcha pela utopia concreta.

Nesse sentido, "a fim de abrir a análise da pluralidade de ordenamentos, sob o pano de fundo da divisão de classes e sem tributo ao pluralismozinho de Santi Romano", Lyra dialoga com o pluralismo jurídico proposto por Boaventura de Sousa de Santos - o marxista, diga-se de passagem, não o pós-moderno dos dias atuais -, uma vez que considera que o marxismo em geral, mesmo os não-dogmáticos por ele trabalhados, caí na armadilha kelseniana de ratificar o monopólio estatal da produção jurídica (LYRA FILHO, 1980a, p.28).

Por esta via, Lyra Filho intenta superar os fantasmas ideológicos do dualismo entre direito natural e direito positivo a partir de uma ontologia dialética do direito. Pois mesmo Bloch, em sua utopia jurídica, "permanece o dualismo - direito positivo e direito natural - como uma antinomia (uma contradição insolúvel), que parte o Direito num ângulo que só vê a ordem e noutro que invoca uma Justiça, cujo fundamento não é adequadamente assentado nas próprias lutas sociais e, sim, em princípios abstratos" (LYRA FILHO, 2006, p.50). A saída, então, não consiste em optar por "um Direito Natural, mesmo de conteúdo mutável, pois este mantém, de toda sorte, um idealismo antidialético, ou no sentido abstrato e desligado da práxis, ou no sentido de antinômico, irresolúvel na totalização e devenir. Também não se trata, é óbvio, de um positivismo" (LYRA FILHO, 1981b, p.24-5). Tal antítese ideológica só se dissolverá, "quando for buscado, no processo histórico-social, aquele estalão [a incorporação das ontologias marxistas]. Mas isto não importa em identificar, simplesmente, Direito e processo histórico e, sim, procurar nesse o aspecto peculiar da práxis jurídica, como algo que surge na vida social e fora dela não tem qualquer fundamento ou sentido" (LYRA FILHO, 2006, p.57-8). Uma dialética social do direito que "abrange, não apenas a formação jurídica visando a estabelecer padrões de controle social, mas o impulso jurígeno, que visa a delinear

aproximação, fortemente, influenciada pela concepção de Coutinho como se verá adiante. (PORTANTIERO, 1981, p.69). 
uma postura crítica e fixar padrões de mudança. E isto inevitavelmente gera uma pluralidade de ordenamentos em conflito e competição, cuja raiz está na infra-estrutura e na divisão da sociedade em classes" (LYRA FILHO, 1980a, p. 31).

A processualidade do direito, então, não se resume à práxis jurídica delineada pelo ordenamento de um Estado em sentido estrito - que consiste, basicamente, nos aparelhos repressivos e em sua ossatura institucional -, mas no Estado Integral, que é constituído pelo conjunto dos meios de direção intelectual e moral (os aparelhos de hegemonia). Tal "ampliação do Estado passa portanto por uma incorporação da hegemonia e de seu aparelho ao Estado. [...] A problemática da ampliação do Estado será envolvida na de correlação de forças, e a sociedade civil será atravessada, do econômico ao ideológico, pela luta de classes (BUCl-GLUCKSMANN, 1980, p.98-110)".

Ao seguir essas pistas, em especial, Lyra filho pensa numa concepção ampliada de direito, tal como o próprio Gramsci insinua em nota, que merece ser reconstituída com a totalidade de seus escritos ${ }^{10}$, que a "Questão do 'direito', cujo conceito deverá ser ampliado, nele incluindo aquelas atividades que hoje são compreendidas na fórmula 'indiferente jurídico' e que são de domínio da sociedade civil, que atua sem 'sanções' e sem 'obrigações' taxativas, mas que nem por isso deixa de exercer uma pressão coletiva e de obter resultados objetivos de elaboração nos costume, nos modos de pensar e de atuar, na moralidade, etc" (GRAMSCI, 2002, p.23-4). Há, portanto, "como notava o líder marxista italiano, Gramsci”, por meio da introdução da ontologia da práxis e a ampliação do Estado, o alargamento do "foco do Direito, abrangendo as pressões coletivas (e até, como veremos, as normas não-estatais de classe e grupos espoliados e oprimidos) que emergem na sociedade civil (nas instituições não ligadas ao Estado) e adotam posições vanguardeiras, como determinados sindicatos, partidos, setores de igrejas, associações profissionais e culturais e outros veículos de engajamento progressista" (LYRA FILHO, 1981b, p.9-10).

10 Este exercício filológico gramsciano não é o objeto do presente estudo, contudo está sendo desenvolvido em tese de doutoramento - A questão do Direito em Gramsci: os (ab) usos da leitura gramsciana na Sociologia do Direito Crítica - a ser defendida em 2017. 
Ao contrário dos outros caminhos tomados pelas abordagens marxistas, Lyra Filho, no tocante a análise histórico-concreta da esfera jurídica, está de acordo com Boaventura, em sua concepção pluralista, para quem "a coesão ideológica de uma sociedade classista é sobreposta a inconciliáveis conflitos de classe, constantemente gerados pelas relações de produção, as classes dominadas - ou grupos específicos dentro delas - tendem a desenvolver subculturas 'legais', que, em certas circunstancias, podem associar-se a uma práxis institucional relativamente autônoma, com variáveis objetivos e nível de organização". Deste modo, "reconhecer esta práxis como 'legal' e este direito como direito paralelo (isto é, caracterizar a situação como pluralismo 'legal') e adotar um ponto de vista teórico, julgando este direito como não inferior ao direito estatal - envolve uma opção científica e política". Por esta via, Lyra realiza a ampliação do conceito do direito por meio da negação do radical monopólio do Estado na produção e circulação da forma jurídica, subvertendo o critério formal de validade escorado em procedimentos estatais e assumindo uma postura politicista baseada nas diversas normatividades presentes na totalidade da práxis social. (SANTOS, 1977, p.25)

Em sua ontologia dialética do direito, Lyra compreende as normatividades jurídicas em sua conflitualidade com o lastro na luta dialética estruturada nas diversas opressões presentes na sociedade. Por este motivo, considera que "no mesmo espaço geopolítico, vigora (oficialmente ou não) mais de uma ordem jurídica" (SANTOS, 1977, p.109). Nesta coexistência os "ordenamentos lutam pela hegemonia, cujas condições de triunfo ou legitimidade sempre dependem da natureza dos posicionamentos e interesses que as normas refletem"( LYRA FILHO, 1980b, p.6).

A batalha incessante pela hegemonia - categoria fundante da ontologia gramsciana e absolutamente utilizada por Lyra - entre as esferas de normatividade somente pode ser compreendida no interior da "luta de classes e grupos, que cinde o bloco demográfico (da população), as oposições de espoliados e espoliadores, de oprimidos e opressores, [que] movimenta a dialética social e, nela, a vertente jurídica" (LYRA FILHO, 2006, p.79). Na verdade, para Lyra, o direito não é o campo 
formal, supracategorial, onde se digladiam uma pluralidade de ordenamentos consubstanciados pelos interesses na luta social, pelo contrário, o direito é identificado, em sua especificidade, como um campo da libertação, aglutinando as tendências contra-hegemônicas, em contradição com o antidireito, que consiste na expressão normativa dos interesses dominantes.

O critério aferidor que distingue os pólos de juridicidade - direito e antidireito - é a concretude da ideia de Justiça. "A contradição entre a injustiça real das normas que apenas se dizem justas e a injustiça que nelas se encontra pertence ao processo, à dialética da realização do Direito, que é uma luta constante entre progressistas e reacionários, entre grupos e classes espoliados e oprimidos e grupos classes espoliadores e opressores" (LYRA FILHO, 2006, p.82). No interior deste contexto de lutas, Lyra define que "Justiça é Justiça Social, antes de tudo: é atualização dos princípios condutores, emergindo nas lutas sociais, para levar à criação duma sociedade em que cessem a exploração e opressão do homem pelo homem; e o Direito não é mais, nem menos, do que a expressão daqueles princípios supremos, enquanto modelo avançado de legitima organização social da liberdade" (LYRA FILHO, 2006,p.86). A especificidade da forma jurídica, para Lyra Filho, portanto, "se apresenta como positivação da liberdade conscientizada e conquistada nas lutas sociais e formula princípios supremos de Justiça Social que nelas se desvenda", encontrando seu critério de validade na práxis de libertação (LYRA FILHO, 2006, p.101-102).

O direito, pois, em sua processualidade histórico-concreta, é "expressão, num ângulo particular e inconfundível, da dialética de dominação-libertação, que constitui a trama, o substrato e a mola do itinerário humano, através dos tempos" (LYRA FILHO, 1981b, p.7). Então, a dialética social do direito, tem sua gênese a partir da infra-estrutura, "formando ordenamentos antitéticos;e tais normas, articuladas na dialética social, serão propriamente jurídicas, na medida em que tendam a estruturar-se em preceituações de peculiar intensidade coercitiva, polarizando-se, de um lado, com aspiração a estabelecer a ordem justa e eficaz e, de outro, como padrões que se reportam à Justiça Social" (LYRA FILHO, 1981b, p.24). Aqui, depreende-se a 
tensão latente ou explícita entre a pluralidade de elaborações normativas decorrentes dos grupos sociais, que compõem o movimento dialético do direito portador, em sua essência, na potencialidade utópico-concreta de transcender (realizar a negação da negação) das formas jurídicas outrora revolucionárias e hoje conservadoras do modo de produção capitalista.

O jurista carioca, apesar da pluralidade de embates sociais existentes e por ele sublinhado em detrimento dos marxistas tradicionais, apoia-se no termo exposto por Lênin ${ }^{11}$, dualidade de poderes ${ }^{12}$ - "o 'poder dual' (isto é, mais de um poder social na dialética de conflito)" (LYRA FILHO, 1981b, p.88), uma vez que reconhece a centralidade da contradição gerada pela alienação do trabalho. Assim, mesmo envolto à diversidade de opressões e demandas específicas, reconhece a presença de um poder estabelecido ancorado no antidireito das classes dominantes e a latência de um poder popular com sua normatividade alternativa, o direito propriamente dito. No entanto, Lyra Filho, na esteira de Boaventura, amplia o conceito - a dualidade de poderes consiste numa excepcionalidade de cisão do bloco histórico em que ocorre um impasse na direção da sociedade no contexto da luta de classes, tendo um desfecho, inevitavelmente, num curto de período para situações de relativa estabilidade na hegemonia política burgue-

11 Sobre a dualidade de poderes, Lênin, em 1917, ao explicar a existência de um poder paralelo ao central na Revolução Russa, explicita que "em que ao lado do Governo Provisório, o governo da burguesia, se formou outro governo, ainda fraco, embrionário, mas indubitavelmente existente de facto e em desenvolvimento: os Sovietes de deputados operários e soldados" (LENINE, 1980, p. 17).

12 As características principais do conceito são: "1) A fonte do poder não está em uma lei discutida e aprovada pelo Parlamento, mas na iniciativa direta das massas populares partindo de baixo e em escala local, 'na conquista direta', para empregar uma expressão corrente; 2) A substituição da policia e do exercito, como instituições separadas do povo e opostas ao povo, pelo armamento de todo povo; com este poder a ordem publica é mantida pelos próprios obreiros e campesinos armados, pelo povo em armas; 3) O funcionalismo, a burocracia, ou são substituídos pelo poder imediato do próprio povo, ou, pelo menos, são colocados sob controle especial e se transformam em pessoas não somente elegíveis, mas também destituíveis a primeira exigência do povo e se reduzem a situação de simples representantes, transformando-se de classe social privilegiada com remuneração elevada, burguesa, em obreiros de uma 'arma' especial, cuja remuneração não exceda o salário normal de um bom obreiro. (SANTOS, 1980, p.249-50). 
sa, transpõe a amplitude da guerra de movimento à guerra de posição, a fim de traçar uma análise concreta e uma práxis política voltada para emergência do direito autêntico.

Nesse sentido, o direito está inserido no processo histórico de libertação do mundo regido pela lógica do capital - a busca pela justiça concreta -, bem como nos dilemas da estratégia revolucionária em direção ao socialismo. Há a bifurcação entre dois caminhos, de acordo com o debate clássico, dessa práxis emancipatória: reforma ou revolução.

O âmbito estratégico da práxis política também figura no campo jurídico, posto que "ou se revela apenas reformista, enquanto visa a absorção de seus princípios e normas pela central do ramo centrípeto, sem atingir as bases da estrutura e os demais aspectos da normação dominadora; ou se mostra revolucionário, isto é, delineia o contraste fundamental, com uma série de princípios e normas que são proposta e prática reestruturadoras, atingindo a infraestrutura e tudo o que sobre ela assenta" (LYRA FILHO, 2006, p.89-90). No entanto, “a ação, reformista ou revolucionária, não é, necessariamente, pacifica ou violenta. Há meras reformas que desencadeiam luta sangrenta; há totais revoluções que preconizam, ao contrário, os meios incruentos (sem derramamento de sangue) e não-ditatoriais. Exemplo das primeiras, entre nós, a Guerra dos Farrapos. Exemplo da segunda é a estratégia do socialismo democrático". Apesar de contrapor as ressalvas devidas - "a acomodação que dissolve os próprios objetivos revolucionários" -, Lyra Filho nutre especial simpatia pelo caminho do socialismo democrático, porém autodelimita o que quer dizer com a expressão: "nós não a empregamos senão com a advertência de que, nela, se procura designar uma superação, evitando quer os desvios aburguesados quer os congelamentos ditatoriais" (LYRA FILHO, 2006, p.81-82).

A opção estratégica de concretização do socialismo e, por sua vez, do direito autêntico emergente dessa nova estrutura social aproxima-se da recepção gramsciana de Carlos Nelson Coutinho e sua noção de um de reformismo revolucionário. Pois, para Coutinho, do mesmo modo que para Lyra Filho, "a 'mudança política radical' pode e deve ser obtida através de um conjunto sistemático de reformas de estrutura, numa estratégia que poderia ser definida como 'reformis- 
mo revolucionário"” (COUTINHO, 1992, p.16-7). Isto é, "por meio da conquista permanente e cumulativa de novos espaços no interior da esfera pública, tanto na sociedade civil quanto no próprio Estado, tornou-se factível inverter progressivamente a correlação de forças, fazendo que, no limite, a classe hegemônica já não seja mais a burguesia, e sim, ao contrário, o conjunto dos trabalhadores" (COUTINHO, 1999, p.57). Tal concepção é inspirada, em sentido contrário à guerra de movimento - tomada do Estado por meio de uma insurreição explosiva e violenta -, na estratégia de guerra de posição formula pelo marxista sardo.

O marxista italiano visualizava nas sociedades ocidentais uma decisiva complexificação na sociedade civil e a necessidade de uma nova estratégia de luta capaz de rearticular o projeto socialista. Por isso, então, não como uma plataforma reformista, Gramsci pensa a necessidade de se travar a luta comunista através de uma guerra de posição "voltada para a ocupação de espaços nesse conjunto de aparelhos privados de hegemonia, com o objetivo de desarticulá-los ou então mudar sua natureza", bem como "a conformação de uma outra sociedade civil, antagônica àquela burguesa e privada, e que tenha por fundamento o espaço público e uma nova cultura capaz de compor uma nova hegemonia" (DEL ROIO, 1998, p.114). Essa guerra de posição, cerne do reformismo-revolucionário, para Coutinho, sustenta-se na ação diretiva com o aprofundamento e radicalização do processo democratização. "No lugar da coerção, quer ela provenha do Estado ou do mercado, do 'poder' ou do 'dinheiro', devemos pôr cada vez mais esferas de consenso, de controle intersubjetivo das interações sociais". A socialização da política - a tal democracia como valor universal - torna-se um elemento fundamente de sua apreensão gramsciana e, plenamente, absorvida pelo pensamento lyriano (COUTINHO, 1998, p.36).

O horizonte estratégico de Lyra aponta, igualmente, para interdependência entre a realização do socialismo e a democratização. Uma vez que "não se corrigem os vícios da democracia liberal, matando a democracia, mas intervindo no processo democrático, a fim de generalizá-lo, com vista a eliminar, progressivamente, os privilégios de 
classe e grupo, além de qualquer distorção do individualismo ou do totalitarismo"(LYRA FILHO,1986, p.293). Em uma demarcação muito clara, observa que "o socialismo caminha pari passu com a democracia, pois 'socialismo autoritário é uma contradição em termos' e 'a democracia política leva ao socialismo, como o socialismo leva à democracia política” (LYRA FILHO, 1983b, p.50). Ainda, Lyra, explicita a opção pelo reformismo-revolucionário à Coutinho, quando afirma que o próprio Marx, "destacava lucidamente a importância do sufrágio universal, como instrumento de libertação (isto é, do caminho para o socialismo, no interior do processo político tradicional). E, diante deste processo recomendava as conquistas pacientes da 'evolução revolucionária' (isto é, da revolução que se processa, mediante reformas)" (LYRA FILHO, 1986, p.293).

Colocada de lado, então, a estratégia revolucionária insurrecional delineada por Lênin, tendo como expressão jurídica "uma teoria marxista contra o Direito", que "deve revelar a negatividade do direito frente ao movimento revolucionário", abre-se a possibilidade de pensar uma teoria e filosofia do direito inserida na práxis revolucionária baseada na perspectiva da guerra de posições. "Uma sofisticada teoria marxista do Direito" que integre "uma estratégia da classe obreira baseada na superação da dicotomia reforma/revolução tal como se manifesta historicamente. Isto implica na utilização não burguesa da legalidade burguesa e a criação e expansão das instancias de legalidade socialista alternativa" (SANTOS, 1980, p.246-47). Assim, embora Lyra Filho não se imponha essa tarefa propriamente dita, uma vez que rejeita a própria denominação de sua proposta como marxista e afirma-se como proponente de uma nova teoria crítica do direito, traceja uma práxis jurídica socialista de, no mínimo, forte inspiração marxista.

Nesse sentido, Lyra Filho, no interior de uma estratégia de gradual transformação da sociedade capitalista, constrói sua crítica jurídica a partir da extração de elementos das três grandes ontologias marxistas do século $X X$ : de Lukács, a ontologia enquanto um esforço materialista de captar a essência do direito em sua profunda historicidade e articulação dialética; a partir de Bloch, capta a noção de 
utopia concreta baseada na categoria de possibilidade presente nas latências da realidade, abordando às potencialidades de um direito que ainda-não-é; por último, recoloca a centralidade da ideia de práxis estruturada em torno da teoria da hegemonia em Gramsci, observando que há uma batalha entre normatividades para além de sua expressão estatal. Entretanto, não é esse esforço metódico criativo de Lyra que o afasta do marxismo, mas a negação da consequência que cada um desses autores imprime para sua teoria do direito: a especificidade da forma jurídica enquanto mediação intrínseca à reprodução do capital e o imperativo da extinção de tal espaço de mediação social alienado.

O antinormativismo de Lyra Filho, através da incorporação do pluralismo jurídico à Boaventura, acaba por distanciá-lo da crítica do direito marxista, uma vez que, em especial pelo (ab)uso fragmentário do pensamento gramsciano, avalia a existência de uma dialética social das normas representada pela sua cisão em conflitos hegemônicos de ordenamentos jurídicos plurais presentes no mundo do capital. $\mathrm{E}$, por isso, ao invés de atrelar a estrutura jurídica a uma relação genética com o modo de produção capitalista, observa uma potencialidade de negação da negação do direito dentro da dialética dominação-libertação. Em suma, tal alternatividade ao direito burguês com a constituição de outro direito possível calcado na luta dos oprimidos em suas virtualidades utópico-concretas, confere à forma jurídica um caráter positivo/libertador por meio da possibilidade sempre latente de uma práxis jurídica emancipatória. É, justamente, esta questão que o aproxima de certo socialismo jurídico impulsionado por um também sui generis jusnaturalismo histórico derivado da normatividade produzida/reivindicada pelos diversos grupos e movimentos sociais.

Um panorama crítico dos resultados da ontologia dialética do direito formulada por Lyra Filho, portanto, em sua aproximação e usos das ontologias marxistas ainda é terreno fértil e pouco explorado. Há, além do forte caráter ensaístico das obras de Lyra, na verdade, uma dupla interdição desta temática derivada da contradição exposta acima: uma negação da própria crítica marxista ao direito, exacerbada pelo caráter 
polemista de Lyra, da apropriação e malabarismos categoriais produzidos pela originalidade de seu pensamento em identificá-lo como parte da tradição marxista - rotulo que nem ele, a bem da verdade, fazia questão de estampar; e, por outro lado, uma vertente alternativista, que reivindica a centralidade da práxis jurídica popular e considera os aportes marxistas importantes, mas ressaltam uma identidade autônoma dentro da heterogeneidade das chamadas teorias críticas do direito latino-americanas.

Por óbvio, a superação dessas barreiras não significa uma aceitação acrítica do inestimável legado de Lyra Filho, tampouco uma abordagem inquisitorial cercada de filologia marxiana resume as possibilidades apreensão de seu pensamento, mas é necessário, para teoria/ filosofia do direito marxista - compreendida a partir dos elos entre uma crítica estrutural do direito (ontológica), uma postura antinormativista e a possibilidade de uma práxis jurídica insurgente dentro dos limites impostos pela forma jurídica -, analisar a capacidade de diagnóstico e projeção da realidade constituída pela potente e original crítica esboçada em sua ontologia dialética do direito.

Dentre tantos caminhos possíveis para trilhar esse caminho em um autor tão multifacetado do plano jurídico, optou-se por ressaltar seu ambicioso projeto de uma crítica original (ontologia dialética do direito), porém, profundamente, enraizada nas grandes ontologias marxistas do século XX. É clara, portanto, a presença central do aporte ontológico marxista (Lukács, Bloch e Gramsci): os gritantes extratos de uma ontologia marxista do direito em Lyra Filho. Um marxismo heterodoxo, que (ab)usa de elementos categoriais dissociados da totalidade do texto destes importantes marxistas, mas, ainda assim, uma obra que comporta um marxismo criativo e inacabado em seus nexos. Um conjunto de escritos que, mesmo quando sistemático, é portador de uma rajada de acidas adjetivações próprias da oralidade e fecundas contribuições, contudo é uma obra em movimento em suas tão brilhantes quanto incompletas formulações. Como ele próprio gostaria, seu texto não deve ser petrificado por dogmatizações indentitárias sob a alcunha que for, mas deve ser explorado pelo que 
ele ainda-não-é em suas virtualidades para permanecer vivo no horizonte estratégico socialista.

\section{REFERÊNCIAS}

ALBORNOZ, Suzana. Ética e Utopia: ensaio sobre Ernst Bloch. Porto Alegre: Movimento, 1985.

BLOCH, Ernst. O Principio Esperança. Vol. 1. Rio de Janeiro: EdUERJ: Contraponto, 2005.

. O Principio Esperança. Vol. 2. Rio de Janeiro: EdUERJ:

Contraponto, 2006.

lar, 1980.

. Derecho Natural y Dignidad Humana. Madri: Agui-

BUCI-GLUCKSMANN, Christine. Gramsci e o Estado: por uma teoria materialista da filosofia. Rio de Janeiro: Paz e Terra, 1980.

COUTINHO, Carlos Nelson. Democracia e socialismo. São Paulo: Cortez, 1992.

. Lukács, a ontologia e a política. In: Marxismo e Política: a dualidade de poderes e outros ensaios. São Paulo: Cortez, 1996.

22, 41-59, 1999.

Cidadania e Modernidade. Perspectivas, São Paulo, Socialismo e democracia: a atualidade de Gramsci. In: AGGIO, Alberto (org.). Gramsci : a vitalidade de um pensamento .São Paulo : UNESP, 1998.

DEL ROIO, Marcos. Gramsci contra o Ocidente. In: AGGIO, Alberto (org.). Gramsci : a vitalidade de um pensamento .São Paulo : UNESP, 1998.

FURTER, Pierre. Dialética da Esperança. Rio de Janeiro: Paz e Terra, 1974. 
GRAMSCI, Antonio. Cadernos do cárcere: Maquiavel, notas sobre o Estado e a Política (v.3). Rio de Janeiro: Civilização Brasileira, 2002.

LENINE, Vladimir llich. Sobre a dualidade poderes. In: LENINE, Vladimir llich. Obras escolhidas (V.2). São Paulo: Alfa-Ômega, 1980.

LESSA, Sergio. Para compreender a ontologia de Lukács. ljuí: Editora Unijuí, 2007.

Mundo dos homens: trabalho e ser social, São Paulo: Boitempo, 2002.

. Lukács: por que uma ontologia no século XX?. In: Boito Jr. Armando e outros. A Obra Teórica de Marx. Atualidade, problemas e interpretações. São Paulo, Xamã, 2000.

. Notas sobre a historicidade da essência em Lukács. Novos Rumos, São Paulo, v. 30, p.22-30, 1999.

.0 reflexo como "não-ser" na ontologia de Lukács: uma polêmica de décadas. Revista Crítica Marxista, São Paulo, n.4, p.89-112, 1997.

LUKÁCS, György. Ontologia do Ser Social: os princípios ontológicos fundamentais de Marx. São Paulo: Livraria Editora Ciência Humanas, 1979.

niti, 1981.

.Per l'ontologia dell'essere sociale. II*. Roma: Riu-

. Per l'ontologia dell'essere sociale. II**. Roma: Riuniti, 1981.

LYRA FILHO, Roberto. O que é direito. São Paulo: Brasiliense, 2006. . Desordem e Processo: um pósfacio explicativo. In: ARAUJO LYRA, Deodoro (Org.). Desordem e Processo: estudos sobre o direito em homenagem a Roberto Lyra Filho, na ocasião de seu 60 aniversário. Porto Alegre: Fabris, 1986. 
. Pesquisa em que Direito? Brasília: Nair, 1984.

. Karl, meu amigo: Diálogo com Marx sobre o direito.

Porto Alegre: Fabris, 1983a.

Humanismo Dialético. Direito e Avesso, Brasília, Ano II, n.3, p.15-103, 1983b.

Problemas Atuais do Ensino Jurídico. Brasília: Editora Obreira, 1981a.

- Razões de Defesa do Direito. Brasília: Editora Obreira, 1981b.

. Para um direito sem dogmas. Porto Alegre: Fabris, 1980a.

O direito que se ensina errado. Brasília: Centro Acadêmico de Direito da UNB, $1980 \mathrm{~b}$.

MASCARO, Alysson Leandro. Utopia e Direito: Ernst Bloch e a Ontologia Jurídica da Utopia. São Paulo: Quartier Latin, 2008.

MÜNSTER, Arno. Ernst Bloch: filosofia da práxis e utopia concreta. São Paulo: UNESP, 1993.

OLDRINI, Guido. Em busca das raízes da ontologia (marxista) de Lukács. In: LESSA, Sergio; PINASSI, Maria Orlanda (orgs.). Lukács e a atualidade do marxismo. São Paulo: Boitempo, 2002.

PORTANTIERO, Juan Carlos. Los usos de Gramsci. México: Folios, 1981.

SANTOS, Souza Boaventura. The Law of the Oppressed: The Construction and Reproduction of Legality in Pasargada. Law and Society Review, Denver, v.12, n.1, p.5-126, 1977.

\section{Justicia Popular, Dualidad de Poderes y Estrategia}

Socialista. Papers: Revista de Sociología, Barcelona, n. 13, 243263, 1980. 
TERTULIAN, Nicolas. Uma apresentação à Ontologia do Ser Social, de Lukács. Revista Crítica Marxista, São Paulo, n.3, p.54-69, 1996.

. Lukács Hoje. In: LESSA, Sergio; PINASSI, Maria Orlanda (orgs.). Lukács e a atualidade do marxismo. São Paulo: Boitempo, 2002.

Recebido: 1\%05/2016 Aceito: 30/08/2016 